\title{
PROFITABILITY OF TECHNICAL TRADING STRATEGIES IN \\ EMERGING SRI LANKAN STOCK MARKET
}

\author{
P.N.D. FERNANDO \\ Department of Finance, University of Kelaniya, Sri Lanka \\ pndfernando@kln.ac.lk
}

\begin{abstract}
This study examines whether the technical trading strategies can outperform the unconditional buy-and-hold strategy to forecast stock price movements and earn excess returns, after adjusting transaction costs, in emerging Colombo Stock Exchange (CSE). The study uses daily market closing prices of All Share Price Index (ASPI), which is a composite index to represent whole market, for twenty five years from January 1985 to December 2010. The variable length moving average method and fixed length moving average method with sixteen different rules is used as the methodology to analyze data. The empirical findings of the study confirmed that the moving average trading strategies have statistically significant predictive ability in explaining the market and capable of generating excess return to investors. However after considering transaction costs the excess return is negligible.
\end{abstract}

Key words: emerging, moving average, outperform, trading strategies.

\section{Background of the Study}

The method of explaining and forecasting the future patterns of stock prices, the technical analysis, is started even before the 1800. Technical analysis is considered as one of the preliminary methods of investment analysis because stock prices and volume figures have been publicly available prior to any other types of financial information (Lenton, 2008). The technicians or the chartists always believed that the history will bound to repeat in the market. With that intention technicians used historical price and volume figures to predict about the market. They employed a number of charts, and diagrams to explain the market situations and market trends. Technical analysis is being extensively used by brokerage firms, foreign exchange dealers, investors, and commodities traders. The school of thought who believe that the price of stock is determine not only by previous price and volume data but also with the help of firm specific financial and macro level data, developed the Fundamental analysis to 
explain the stock prices. But still technicians emphasize the value of Technical analysis because of Accounting irregularities and scandals.

Throughout the period researchers documented the importance of technical analysis and its applicability in identifying profitable price patterns in many ways. Brock, Lakonishok, \& LeBaron (1992) tested data obtained for two simple technical strategies on the Dow Jones Industrial Average from 1897 to 1986 . All the trading strategies generated higher mean returns than the benchmark buy and hold returns, prior to transaction cost. Blume, Easley, \& O'Hara (1994) documented a model to explain that the investors learn from both past prices and volume figures. They also showed that the traders who use information contained in market statistics perform better than those who do not. Their concluding remarks mentioned that the value of technical analysis may be more appropriate for small stocks rather than large stocks. Bessembinder \& Chan (1998) confirmed the statistical significance of Brock et al. (1992) results but it lost the economic significance once they considered the transaction costs. Further they emphasis the importance of considering transaction costs in evaluating the profitability of technical trading strategies. Chandrashekar (2005) studied the profitability of technical trading strategies across different market capitalization segments using ten CRSP (NYSE, AMEX, and NASDAQ) size deciles index data from 1963 to 2002. The results showed that the success of the trading strategies declines sharply with an increase in firm size. Smaller stocks earned excess average monthly returns nearly two percent, even after adjusting for aggregate risk factors such as momentum, book-to-market, size, market, and liquidity.

It is difficult to overstate the importance of a stock market for a developing country. The primary benefits of a well functioning stock market can be stated as; a) mobilization of savings, b) fund term matching with efficient allocation of investment resources, and c) acceleration of economic growth. Share markets facilitate investors with excess funds to invest them in a profitable way as well as for companies to raise their capital requirements through shares, debentures and any other securities. In Sri Lanka these transactions are take place through Colombo Stock Exchange (CSE).

In recent decades emerging stock markets showed remarkable potential to catch the attention of global investors. Being an emerging stock market the potentiality of CSE was exceptional. In October 2010, Bloomberg cited CSE as the world's best performing share market outshining its own previous stint as "world's second best bourse". 
This study attempts to find out the applicability of Technical trading strategies in a profitable manner to CSE. The conditions above also pertain to identification of the market as being well functioning or efficient. From the investors' point of view, they always expect a welldeveloped and efficient share market to invest their funds.

\section{Review of Previous Studies}

Murphy (1999) defines "technical analysis is the study of market action, primarily through the use of charts, for the purpose of forecasting future price trends". According to this possibility of forecasting the future of security prices is acceptable. Researchers advocated in favor of efficient market hypothesis, emphasis the random walk nature of stock prices and reject the technical analysis and profitability of technical trading strategies. Alexander (1964) mentioned about the inability of certain filter strategies to generate abnormal profits after considering transaction costs. Further the findings of Fama \& Blume (1966) confirmed the fact that the inability of generating superior results from filter rules relative to buy and hold strategies.

James (1968) analyzed the forecasting power of common stocks listed on New York Stock Exchange from 1926 to 1960 . The study considered two kinds of stock prices, one adjusted for dividends and other unadjusted for dividends and methodology applied for the study consisted with monthly unweighted moving average and exponentially smoothed moving average. The concluding remarks of the study rejected the ability of benefits to investors by using monthly moving average as a forecasting technique.

The scholarly article of Brock et al. (1992) changed the direction of thinking pattern related with technical trading strategies in forecasting the future stock price patterns. Their study used ninety years data series of Dow Jones Industrial Average (DJIA) from 1897 to 1986. All the stocks include in the DJIA are very actively traded and the problem of nonsynchronous trading is negligible. The study divide the full sample into four subsamples to compare the results within the sample period selected. Their methodology consists with moving averageoscillator and trading range break-out which are simple and most widely used technical trading rules by traders. Further they used bootstrap methodology to confirm the results obtain from moving averages and trading range brake-out rules. The conclusions of the study confirmed the predictive power of technical trading rules. Though the study endorsed the predictability of stock prices, they didn't concern about the profitability of technical trading rules after considering transaction costs in a costly trading environment. 
Hudson, Dempsey, \& Keasey (1996) studied the applicability of technical trading strategies in to UK stock market. The study basically followed the method adopted by Brock et al. (1992). They used Financial Times Industrial Ordinary Index data from 1935 to 1994. The index is calculated on the basis of thirty UK companies representing major manufacturing and service companies. This study further focused on the ability of earning excess returns through technical trading strategies in a costly trading environment. The study divided the total sample period in to four sub-periods to represent different economic regimes in the country. Results of the first two sub- periods provide significant outcomes but others were not. In contrast to this, none of the sub-periods reported by Brock et.al (1992) were significant. Although the returns from variable moving average rules are significantly different from buy and hold strategy and generating predictive ability, most of the significantly different returns were negative. This leads to the question of applicability of technical trading strategies as a profitable investment strategy and its sustainability. Further the study emphasis on the requirement of longer period for a better predictability. They concluded that the UK data do have some predictive ability with reference to technical trading strategies but the excess return is diluted due to costly trading environment.

In the study of Bessembinder \& Chan (1995) assessed the predictability of stock prices in Asian markets through simple technical trading rules. The results of the study confirmed the predictive ability of technical trading rules in explaining price changes in Japan, Hong Kong, South Korea, Malaysia, Thailand, and Taiwan. Further their study explained the dilution of profitability due to inclusion of transaction costs. This study explained about the cross-market correlation in the signals produced by the technical rules and further elaborated the ability of applying the methodology used for developed markets and obtaining the same results. Bessembinder \& Chan (1998) further investigated the explanation given by Brock et al. (1992). They confirmed the results of Brock et al. but they pointed out that the outcome can consistent with the idea of market efficiency when considering transaction costs.

The study of Ratner \& Leal (1999) examined the profitability of technical trading strategies in ten emerging markets in Latin America and Asia. The study used daily inflation adjusted returns from January 1982 to April 1995 and employed ten different variable moving average models and assessed through bootstrapping simulation. Further the study considered the data relating to U.S and Japan for the same time period with a view of comparing the results. The findings of the study confirmed that the ability of forecasting future price movements in profitable manner is not extensive. The study found five profitable strategies after 
considering transaction costs in Mexico and Taiwan, three strategies for Thailand, two strategies for Philippines, one for Brazil, Japan, Korea, and Malaysia and none for Argentia, Chile, India, and US.

The classical study of Bokhari, Cai, Hudson, \& Keasey (2005) investigated the predictive ability and profitability of the technical trading strategies for different size companies. The study considered sample of 100 UK stocks from London stock exchange from January 1987 to July 2002. The 100 stocks sample consists of 33 randomly selected companies from the FTSE 100, 33 randomly selected companies from the FTSE 250, and 34 randomly selected companies from FTSE Small Cap. They concluded that the predictive ability of the technical trading strategies are higher with small capitalization companies but cannot be used in a profitable manner when appropriate transaction costs introduced.

Metghaalchi et al. (2007) analyzed the daily index prices of the Australian stock market from January 1990 to May 2006. They computed daily returns as the change in logarithmic daily index data and used moving average strategies to study predictability and profitability of prices. The results of the study confirmed the hypothesis that technical trading strategies can outperform the buy-and-hold strategy and the ability of earning profits after considering break even transaction cost.

The research work of Gunasekarage \& Power (2001) studied about the predictability of moving average rules in the South Asian stock markets. The study has selected four stock markets in India, Sri Lanka, Pakistan, and Bangladesh. Sample period of the study consists from 1990 to 2000. The study concluded with convincing evidences regarding the predictability of equity returns in these markets. Though the study mainly followed the methods adopted by Brock et al. (1992) and Hudsan et al. (1996) conclusions were contrast with them. Those US and UK studies found clear evidences for rising markets but this study does not find any evidence for upward trending markets. The based two studies emphasis the requirement of longer time period data in explaining predictive ability but this study used shorter time period data for explaining predictive ability. Finally, those two studies stressed that sell signals to be more powerful than buy signals in predicting future trends in share returns, while the study confirmed that importance of both buy and sell signals in predicting future trends.

Pathirawasam and Kral (2012) examined the momentum effect in Colombo Stock Exchange from 1995 to 2008. Quarterly momentum strategies were formed taking all the voting stocks 
traded at CSE. The study found medium term momentum profits and momentum effect is stronger in the down-market stance than in the up-market stance.

All the market efficiency studies relating to CSE, except Gunasekarage \& Power (1995) and Pathirawasam and Kral (2012), used index return data. Gunasekarage \& Power (1995) employed data relating to individual companies listed in CSE and concluded with the evidence confirming weak-form efficiency of the market. The significance of the results of their study is limited by the time period considered, it was only sixteen months. This vacuum is encouraging more research on employing individual company data for a longer time period. On the contrary, except Gunasekarage \& Power (2001) all the other studies relating to efficiency of CSE applied the statistical tests to check the independence of returns. Only Gunasekarage \& Power (2001) employed moving average strategy to test the weak-form efficiency. This void is also encouraging to use more technical trading strategies and moving average strategies in more detail to test the profitability on CSE.

\section{Methodology of the Study}

This study mainly based on the secondary data obtained from CSE. The study analyses the daily index closing prices of All Share Price Index (ASPI) from $2^{\text {nd }}$ January 1985 to 31 st December 2010, a total of twenty five years of daily closing prices, approximately 6208 data items. Daily index closing prices are converted to daily return figures using the following formula.

$$
R_{t}=\operatorname{Ln}\left(P_{t}\right)-\operatorname{Ln}\left(P_{t-1}\right)
$$

The return on the day $t\left(R_{t}\right)$ is calculated by deducting the $\log$ value of the index on day $t-1(p$ $\mathrm{t}-1)$ from the $\log$ value on day $\mathrm{t}\left(\mathrm{p}_{\mathrm{t}}\right)$.

\section{Moving Average Strategies}

The major analysis of this study employs the observation of returns for the technical trading strategies and compare with the returns earned by the simple buy-and-hold strategy. The present study use the moving average rules and trading range breakout rule employed by Brock et al. (1992), Hudson et al. (1996), and Bessembinder \& Chan (1995, 1998).

The study considers two moving averages, one as short term moving average and the other as long term moving average. The simplest form of moving average strategy is to buy (sell) when the short-term moving average rises above (fall below) the long-term moving average. When the short-term moving average penetrates the long-term moving average, a trend 
begins (Brock et al., 1992). Traders make buy and sell decisions by comparing short-term moving average of a selected security with its long-term moving average. Brock et al. (1992) introduced a bandwidth to moving averages to avoid the whiplash signals generated from continues penetrations of two moving averages. The band introduced is a percentage difference between short and long term moving averages. This band will remove the whiplash signals and automatically reduce the number of buy and sell signals. When short-term moving average is within the band, such situation is identified as a natural signal (no signal is generated). This study tested the moving averages with $0 \%$ and $1 \%$, bands.

To be with this rule an investor should buy (sell) at the closing price of the trading day immediately after the short-term moving average exceeds (fall below) the long-term moving average. Following the existing literature this study tested the VMA rule in CSE by comparing 1 day and 2 day short-term moving averages with 50, 100, 150, and 200 days long-term moving averages including a $0 \%$ and $1 \%$ bands. All together this study considered sixteen VMA rules.

The second version of the moving average rule is the fixed length moving average (FMA), which considers the returns for a fixed length time period. FMA focuses on the crossover of the long-term moving average by the short-term moving average. According to Brock et al. (1992) the FMA trading rule identifies a buy (sell) signal when the short-term moving average cuts the long-term moving average from below (above). Difference between VMA and FMA identified with referring to time period investors stay with each signal. Under FMA rule investors stay in the same position (buy or sell) for a fixed number of days, once a buy or sell signal is identified. In this study for testing FMA 1 day and 2 days short periods and 50, 100, 150, and 200 days long periods with $0 \%$ and $1 \%$, bands are considered. All together it comes to sixteen FMA rules and throughout the study thirty two moving average rules tested with the available data from CSE.

\section{Predictability of Technical Trading Strategies}

Technical trading strategies are in a position to outperform the simple buy-and-hold strategy (Brock et al., 1992). On average positive and negative returns generated from buy and sell signals are significantly different from the returned earned by a simple buy-and-hold strategy. Following the similar methodology adapted in Brock et al. (1992), this study analyzes the predictability of technical trading strategies. Technical trading strategies are considered to be effective if buy signals earn positive returns and sell signals earn negative returns, and are 
statistically significantly different from the returns earned by the unconditional buy-and-hold strategy.

Mean buy and sell returns are calculated by using the following formulas.

$$
\begin{aligned}
& \mu_{(b)}=\frac{1}{N(b)} \sum R_{b} \\
& \mu_{(s)}=\frac{1}{N(s)} \sum R_{s}
\end{aligned}
$$

Where,

$\mu_{(b)} \quad$ : mean returns for buy signals

$\mu_{(\mathrm{s})} \quad$ : mean returns for sell signals

$\mathrm{N}(\mathrm{b}) \quad$ : total number of buy days

$\mathrm{N}(\mathrm{s}) \quad$ : total number of sell days

$\mathrm{R}_{\mathrm{b}} \quad$ : daily returns of buy

$\mathrm{R}_{\mathrm{s}} \quad$ : daily returns of sell

Unconditional simple buy-and-hold return is calculated with following formula.

$$
r_{t}=\left(\frac{1}{n}\right) \sum\left(\ln \left(p_{t}\right)-\ln \left(p_{t-1}\right)\right)
$$

Where,

$\mathrm{r}_{\mathrm{t}} \quad$ : Unconditional mean return at day $\mathrm{t}$

n : number of observations

$\mathrm{p}_{\mathrm{t}} \quad$ : index price level at day $\mathrm{t}$

$\mathrm{p}_{\mathrm{t}-1} \quad$ : index price level at day $\mathrm{t}-1$

ln : natural log values

Unconditional ten days (non-overlapping 10 days taken) returns are calculated by using following formula.

$$
r_{t}=\ln \left(p_{t}\right)-\ln \left(p_{t-9}\right)
$$

Two tailed t-test used to check the significance of the returns generated by the technical trading rules. This study employs the t-tests to test the mean buy returns, mean sell returns, and buy-sell differences. Following formula is used to check the mean buy and sell returns. 


$$
\frac{\mu_{r}-\mu}{\left(\frac{\sigma^{2}}{N}+\frac{\sigma^{2}}{N_{r}}\right)^{1 / 2}}
$$

Where,

$$
\begin{array}{ll}
\mu_{\mathrm{r}} & : \text { mean return (buy or sell) } \\
\mathrm{N}_{\mathrm{r}} & \text { : number of signals (buy or sell) } \\
\mu & \text { : unconditional mean return } \\
\mathrm{N} & \text { : number of observations } \\
\sigma^{2} & \text { : estimated variance for entire sample }
\end{array}
$$

Following formula is employed to calculate t-statistics for the buy-sell differences,

$$
\frac{\mu_{b}-\mu_{s}}{\left(\frac{\sigma^{2}}{N_{b}}+\frac{\sigma^{2}}{N_{s}}\right)^{1 / 2}}
$$

Where,

$$
\begin{array}{ll}
\mu_{\mathrm{b}} & : \text { mean buy returns } \\
\mu_{\mathrm{s}} & : \text { mean sell returns } \\
\mathrm{N}_{\mathrm{b}} & : \text { number of buy signals } \\
\mathrm{N}_{\mathrm{s}} & \text { : number of sell signals } \\
\Sigma^{2} & \text { : variance for entire sample }
\end{array}
$$

Following two hypothesis are generated to compare the active strategies (buy and sell) with passive strategy (buy-and-hold),

Ho: The mean returns generated by technical trading strategies are equal to the returns generated by the buy-and-hold strategy.

H1: The mean returns generate by technical trading strategies are not equal to the returns generated by the buy-and-hold strategy 
The two-tailed t-statistics method employed in this study is used in the same manner by Brock et al. (1992). The null hypothesis will be rejected when the value of the t-statistics is either sufficiently large or small.

\section{Profitability of Technical Trading Strategies}

The present study applied the "double or out" strategy used by Brock et al. (1992) and Bessembinder and Chan $(1995,1998)$ to measure the profits resulting from the application of technical trading strategies in a costly trading environment. The excess returns earned through the strategies can be measured after allowing for transaction costs as well as without considering transaction costs. With relate to CSE Gunasekarage and Power (2001) studied about the excess return without considering transaction costs and concluded by accepting the ability of earning excess returns through technical trading strategies. With reference to that present study planned to analyze the profitability or excess return with considering transaction costs and without considering transaction costs.

Under the double or out strategy, Investors double their investment with a buy signal by borrowing funds at the risk-free rate and sell and invest in risk-free assets with a sell signal. Conversely, the investors are assumed to hold the long position when there is neither a buy signal or sell signal. The logic behind this method is that the investors earn profits when they double their investment with a buy signal by staying in the rising market or bull market. On the other hand, they sell their investments with a sell signal and earn profits by leaving the declining stock market or bear market. The profit from leaving the market under a sell signal can be considered as a cost saving for not being in the declining market. This study assumes that the borrowing and lending rates prevailing in the market are same and the risk during the buy and sell periods are assumed to be the same. It is common to use a zero interest rate because of the complex differences between borrowing and lending rates, and the possibility of investors using arbitrage portfolios (Cai et al., 2005).

Without transaction costs, the excess return $(\pi)$ generated by technical trading rules relative to a buy and hold strategy is given as follows,

$$
\pi=\sum_{i=1}^{N_{b}}\left(R_{i}\right)-\sum_{j=1}^{N_{S}}\left(R_{j}\right)
$$


Where,

$\mathrm{R}_{\mathrm{i}}$ - index return on day $\mathrm{i}$

$\mathrm{R}_{\mathrm{j}}$ - index return on day $\mathrm{j}$

Above calculation will provide the excess return for the technical trading strategies before considering transaction cost. In a costly environment transaction cost is unavoidable; especially under technical trading strategies the number of transaction will increase on the buy and sell signals. According to the Bessembinder \& Chan $(1995,1998)$ the breakeven round-trip cost $(\mathrm{C})$ is calculated as follows,

$$
C=\frac{\pi}{n_{b}+n_{s}}
$$

Where $n_{b}$ and $n_{s}$ are the number of buy and sell signals generated in the time period considered.

The breakeven round-trip costs calculated here represent the costs needed to offset the additional returns from technical trading strategies (Bessembinder \& Chan, 1998).

\section{Analysis of Moving Average Strategies}

Table 1.1 shows the results for variable length moving average strategies for the ASPI. The variable length moving average rule is divide the whole sample in to either buy or sell periods on the basis of relative position of the moving average. If the short-term moving average rises above (falls below) the long-term moving average, the signal is identified as a buy (sell) signal. Following these signals traders decide to stay with the market or moving away from the market.

If the technical trading rules do not have predictive power to forecast share price changes in advance, then the returns on days with buy signals do not differ with returns on days with sell signals. To evaluate the forecasting ability of technical trading strategies, this study compares the mean buy return and mean sell return with unconditional buy-and-hold strategy.

The 16 VMA rules applied in the study shows that all the rules generate positive returns for buy signals and all the sell signals generate negative returns. On an average a buy signals generates a positive one day return of $0.16 \%$ which is approximately $47 \%$ per annum. At the same time, sell signals generates average negative one day return of $-0.064 \%$ which is approximately $-14.25 \%$ per annum. These returns compare with unconditional mean one day 
return of $0.068 \%$, which is approximately $17.7 \%$ per annum. Highest buy returns are generated with $(2,50,0),(2,50,0.01)$, and $(1,50,0)$ and this indicate the predictability of short-time horizons.

Table 1.1 shows that all buy returns as well as sell returns are statistically significant at $1 \%$ level. For the technical trading strategies to be successful the average buy returns must be positive and average sell returns must be negative, and are statistically significantly different from the unconditional buy-and-hold strategy (Brock et al. 1992).

The fixed length moving average strategy considered the return of fixed ten days which starts with the crossing of two moving averages. This method identify the buy and sell signals by examining the crossing points of short and long moving averages, and the returns computed by using the price changes over ten days post signal holding period. Then theses returns are compared with the ten days unconditional mean returns. Table 1.2 reports the results relating to fixed length moving average strategy. All the buy-sell differences are positive for each FMA rule. The average ten day buy returns across sixteen trading strategies are $1.42 \%$ and average ten day sell returns are $0.261 \%$. On an annual basis it generates $40.17 \%$ buy returns and $-6.09 \%$ sell returns. On an average buy and sell returns are significantly different from unconditional buy-and-hold strategy. Number of buy and sell signals generated under FMA strategy is less than the signals generated in the VMA strategy. This smaller number of signals in FMA strategy leads to a higher profits than that of VMA strategy. For example, buy returns under FMA strategy stands at 0.142 which is greater than the buy return under VMA strategy of 0.0016. Results obtained under VMA and FMA strategies are in line with the results of Gunasekarage \& Power (2001). These evidences suggest that the FMA strategies outperformed the VMA strategies in CSE for the time period considered under this study.

Table 1.1 Standard test results for the variable-length moving average (VMA) rules - ASPI

\begin{tabular}{|c|c|c|r|r|r|}
\hline Rules & $\mathbf{N}($ Buy) & $\mathbf{N}($ Sell) & $\boldsymbol{\mu}$ (Buy) Ret & $\boldsymbol{\mu}$ (Sell) Ret & Buy-Sell \\
\hline$(1,50,0)$ & 3518 & 2640 & $0.001802885^{* * *}$ & $-0.000768558^{* * *}$ & $0.002571442 * * *$ \\
& & & $(4.7068)$ & $(-5.4948)$ & $(8.8273)$ \\
\hline$(1,50,0.01)$ & 3362 & 2396 & $0.001656287 * * *$ & $-0.000669374 * * *$ & $0.00232566 * * *$ \\
& & & $(3.9859)$ & $(-4.8973)$ & $(7.6891)$ \\
\hline$(1,100,0)$ & 3585 & 2523 & $0.001584686 * * *$ & $-0.00065057 * * *$ & $0.002235256 * * *$ \\
& & & $(3.8040)$ & $(-4.9922)$ & $(7.6263)$ \\
\hline$(1,100,0.01)$ & 3474 & 2404 & $0.001644412 * * *$ & $-0.000616926 * * *$ & $0.002261339 * * *$ \\
& & & $(3.9873)$ & $(-4.7569)$ & $(7.5573)$ \\
\hline
\end{tabular}




\begin{tabular}{|c|c|c|c|c|c|}
\hline$(1,150,0)$ & 3662 & 2396 & $\begin{array}{r}0.001321302 * * * \\
(2.6969)\end{array}$ & $\begin{array}{r}-0.000379597 * * * * \\
(-3.8852)\end{array}$ & $\begin{array}{r}0.001700899 * * * \\
(5.7168)\end{array}$ \\
\hline$(1,150,0.01)$ & 3596 & 2316 & $\begin{array}{r}0.001320758 * * * \\
(2.6671)\end{array}$ & $\begin{array}{r}-0.000325911 * * * * \\
(-3.6315)\end{array}$ & $\begin{array}{r}0.001646668 * * * \\
(5.4583)\end{array}$ \\
\hline$(1,200,0)$ & 3638 & 2370 & $\begin{array}{r}0.0015291 * * * \\
(3.5239)\end{array}$ & $\begin{array}{r}-0.000425947 * * * \\
(-4.0505)\end{array}$ & $\begin{array}{r}0.001955046 * * * \\
(6.5265)\end{array}$ \\
\hline$(1,200,0.01)$ & 3556 & 2297 & $\begin{array}{r}0.001418456^{* * * *} \\
(3.0232)\end{array}$ & $\begin{array}{r}-0.000370812 * * * \\
(-3.7932)\end{array}$ & $\begin{array}{r}0.001789268 * * * \\
(5.8902)\end{array}$ \\
\hline$(2,50,0)$ & 3519 & 2639 & $\begin{array}{r}0.002048176^{* * * *} \\
(5.7333)\end{array}$ & $\begin{array}{r}-0.001145702 * * * * \\
(-6.9269)\end{array}$ & $\begin{array}{r}0.003193878 * * * \\
(10.9635)\end{array}$ \\
\hline$(2,50,0.01)$ & 3319 & 2443 & $\begin{array}{r}0.002069904 * * * \\
(5.6480)\end{array}$ & $\begin{array}{r}-0.001075286^{* * * *} \\
(-6.4176)\end{array}$ & $\begin{array}{r}0.00314519 * * * \\
(10.4291)\end{array}$ \\
\hline$(2,100,0)$ & 3580 & 2528 & $\begin{array}{r}0.00173064 * * * \\
(4.4175)\end{array}$ & $\begin{array}{r}-0.000869711 * * * \\
(-5.8177)\end{array}$ & $\begin{array}{r}0.002600351^{* * * *} \\
(8.8752)\end{array}$ \\
\hline$(2,100,0.01)$ & 3471 & 2421 & $\begin{array}{r}0.001767296 * * * \\
(4.4975)\end{array}$ & $\begin{array}{r}-0.000834637 * * * * \\
(-5.5705)\end{array}$ & $\begin{array}{r}0.002601933 * * * \\
(8.7127)\end{array}$ \\
\hline$(2,150,0)$ & 3663 & 2395 & $\begin{array}{r}0.001509829 * * * \\
(3.4927)\end{array}$ & $\begin{array}{r}-0.000586541 * * * \\
(-4.6418)\end{array}$ & $\begin{array}{r}0.00209637 * * * \\
(7.0455)\end{array}$ \\
\hline$(2,150,0.01)$ & 3588 & 2315 & $\begin{array}{r}0.001455733 * * * \\
(3.2276)\end{array}$ & $\begin{array}{r}-0.000479501 * * * \\
(-4.1833)\end{array}$ & $\begin{array}{r}0.001935235 * * * \\
(6.4111)\end{array}$ \\
\hline$(2,200,0)$ & 3639 & 2369 & $\begin{array}{r}0.00146218^{* * * *} \\
(3.2435)\end{array}$ & $\begin{array}{r}-0.000545025^{* * *} * \\
(-4.4825)\end{array}$ & $\begin{array}{r}0.002007206^{* * * *} \\
(6.7001)\end{array}$ \\
\hline$(2,200,0.01)$ & 3567 & 2300 & $\begin{array}{r}0.001443765 * * * \\
(3.1325)\end{array}$ & $\begin{array}{r}-0.000504759 * * * \\
(-4.2761)\end{array}$ & $\begin{array}{r}0.001948525 * * * \\
(6.4209)\end{array}$ \\
\hline Average & & & 0.001610338 & -0.000640554 & 0.002250892 \\
\hline
\end{tabular}

Table 1.1 presents the results of the VMA rules for daily data of ASPI from 1985 - 2010. Rules are identified as (short, long, and band). $\mathrm{N}$ (Buy) and $\mathrm{N}$ (Sell) are the number of buy and sell signals generated during the considered sample period. Numbers in parentheses are standard t-statistics using a two-tailed test. T-statistics value is greater than 2.576 indicates statistical significant at $1 \%$ level (indicated with ***), greater than 1.96 indicates statistical significant at 5\% level (indicated with **), and greater than 1.64 indicates statistical significant at $10 \%$ level (indicated with *).

Table 1.2 Standard test results for the fixed-length moving average (FMA) rules - ASPI

\begin{tabular}{|c|c|c|c|c|c|}
\hline Rules & $\mathbf{N}($ Buy $)$ & $\mathbf{N}($ Sell) & $\mu($ Buy $)$ Ret & $\mu($ Sell)Ret & Buy-Sell \\
\hline$(1,50,0)$ & 66 & 66 & $\begin{array}{l}0.013638 \\
(1.259907)\end{array}$ & $\begin{array}{l}0.0005112 \\
(-0.944922)\end{array}$ & $\begin{array}{l}0.013126 \\
(1.559049)\end{array}$ \\
\hline$(1,50,0.01)$ & 52 & 51 & $\begin{array}{l}0.001803 \\
(-0.652972)\end{array}$ & $\begin{array}{l}0.000050 \\
(-0.908913)\end{array}$ & $\begin{array}{l}0.001753 \\
(0.193550)\end{array}$ \\
\hline$(1,100,0)$ & 41 & 40 & $\begin{array}{l}0.012160 \\
(0.802683)\end{array}$ & $\begin{array}{l}-0.007423^{*} \\
(-1.815917)\end{array}$ & $\begin{array}{l}0.019582 * \\
(1.916352)\end{array}$ \\
\hline$(1,100,0.01)$ & 29 & 29 & $\begin{array}{l}0.020050 \\
(1.584296)\end{array}$ & $\begin{array}{l}-0.009065^{*} \\
(-1.747342)\end{array}$ & $\begin{array}{l}0.029115^{* * *} \\
(2.411172)\end{array}$ \\
\hline$(1,150,0)$ & 33 & 32 & $\begin{array}{l}0.014071 \\
(0.952629)\end{array}$ & $\begin{array}{l}-0.017893 * * * \\
(-2.878962)\end{array}$ & $\begin{array}{l}0.031964 * * * \\
(2.791280)\end{array}$ \\
\hline$(1,150,0.01)$ & 28 & 27 & $\begin{array}{l}0.001653 \\
(-0.510767)\end{array}$ & $\begin{array}{l}-0.002151 \\
(-0.921045)\end{array}$ & $\begin{array}{l}0.003805 \\
(0.305620)\end{array}$ \\
\hline$(1,200,0)$ & 27 & 27 & 0.019020 & $-0.016778^{* *}$ & $0.035798 * * *$ \\
\hline
\end{tabular}




\begin{tabular}{|c|c|c|c|c|c|}
\hline & & & (1.398916) & $(-2.531762)$ & $(2.841258)$ \\
\hline$(1,200,0.01)$ & 22 & 22 & $\begin{array}{l}0.013579 \\
(0.726359)\end{array}$ & $\begin{array}{l}-0.012127^{*} \\
(-1.831660)\end{array}$ & $\begin{array}{l}0.025705^{*} \\
(1.841655)\end{array}$ \\
\hline$(2,50,0)$ & 63 & 63 & $\begin{array}{l}0.014241 \\
(1.332841)\end{array}$ & $\begin{array}{l}-0.002528 \\
(-1.425191)\end{array}$ & $\begin{array}{l}0.016769 * * \\
(2.047677)\end{array}$ \\
\hline$(2,50,0.01)$ & 51 & 50 & $\begin{array}{l}0.018394 * \\
(1.830047)\end{array}$ & $\begin{array}{l}0.002073 \\
(-0.601338)\end{array}$ & $\begin{array}{l}0.016322^{*} \\
(1.784284)\end{array}$ \\
\hline$(2,100,0)$ & 36 & 35 & $\begin{array}{l}0.017962 \\
(1.490866)\end{array}$ & $\begin{array}{l}-0.012651 * * \\
(-2.359360)\end{array}$ & $\begin{array}{l}0.030613 * * * \\
(2.804749)\end{array}$ \\
\hline$(2,100,0.01)$ & 26 & 25 & $\begin{array}{l}0.026025 * * \\
(2.152521)\end{array}$ & $\begin{array}{l}-0.011166 * \\
(-1.851460)\end{array}$ & $\begin{array}{l}0.037191 * * * \\
(2.887619)\end{array}$ \\
\hline$(2,150,0)$ & 34 & 31 & $\begin{array}{l}0.017937 \\
(1.441440)\end{array}$ & $\begin{array}{l}-0.015128 * * \\
(-2.510492)\end{array}$ & $\begin{array}{l}0.033065 * * * \\
(2.884668)\end{array}$ \\
\hline$(2,150,0.01)$ & 27 & 26 & $\begin{array}{l}0.016494 \\
(1.132659)\end{array}$ & $\begin{array}{l}-0.018661 * * * \\
(-2.690383)\end{array}$ & $\begin{array}{l}0.035154 * * * \\
(2.771907)\end{array}$ \\
\hline$(2,200,0)$ & 28 & 27 & $\begin{array}{l}0.020401 \\
(1.577730)\end{array}$ & $\begin{array}{l}-0.018208 * * * \\
(-2.688806)\end{array}$ & $\begin{array}{l}0.038609 * * * \\
(3.092104)\end{array}$ \\
\hline$(2,200,0.01)$ & 23 & 22 & $\begin{array}{l}0.025335^{*} \\
(1.937295)\end{array}$ & $\begin{array}{l}-0.015194 * * \\
(-2.136943)\end{array}$ & $\begin{array}{l}0.040529 * * * \\
(2.935787)\end{array}$ \\
\hline Average & & & 0.014171125 & -0.002614113 & 0.005018313 \\
\hline
\end{tabular}

Table 1.2 presents the results of the FMA rules for daily data of ASPI from 1985 - 2010. Rules are identified as (short, long, and band). N (Buy) and $\mathrm{N}$ (Sell) are the number of buy and sell signals generated during the considered sample period. Numbers in parentheses are standard t-statistics using a two-tailed test. T-statistics value is greater than 2.576 indicates statistical significant at $1 \%$ level (indicated with $* * *$ ), greater than 1.96 indicates statistical significant at 5\% level (indicated with **), and greater than 1.64 indicates statistical significant at $10 \%$ level (indicated with *).

\section{Excess Return and Profitability of Technical Trading Strategies}

The profits of technical trading strategies mainly depend on 1) the trading strategy, 2) mean returns on buy days versus mean returns on sell days, and 3) the magnitude of transaction costs when the buy and sell positions are changed (Ratner \& Leal, 1999). Using "double or out" method present study has calculated additional returns $(\pi)$ before transaction costs. Then compute the breakeven transaction costs and compared with the estimated actual transaction costs.

Table 1.3 Breakeven Transaction Cost for VMA and FMA Rules

\begin{tabular}{|l|r|r|}
\hline \multirow{2}{*}{ Rules } & \multicolumn{2}{|c|}{ ASPI (\%) } \\
\cline { 2 - 3 } & VMA & FMA \\
\hline$(1,50,0)$ & 0.14 & 0.08 \\
\hline$(1,50, .01)$ & 0.12 & 0.09 \\
\hline$(1,100,0)$ & 0.12 & 0.12 \\
\hline$(1,100, .01)$ & 0.12 & 0.16 \\
\hline$(1,150,0)$ & 0.09 & 0.18 \\
\hline
\end{tabular}




\begin{tabular}{|l|l|l|}
\hline$(1,150, .01)$ & 0.09 & 0.19 \\
\hline$(1,200,0)$ & 0.11 & 0.21 \\
\hline$(1,200, .01)$ & 0.10 & 0.14 \\
\hline$(2,50,0)$ & 0.17 & 0.10 \\
\hline$(2,50, .01)$ & 0.16 & 0.09 \\
\hline$(2,100,0)$ & 0.14 & 0.18 \\
\hline$(2,100, .01)$ & 0.14 & 0.20 \\
\hline$(2,150,0)$ & 0.11 & 0.19 \\
\hline$(2,150, .01)$ & 0.11 & 0.19 \\
\hline$(2,200,0)$ & 0.11 & 0.22 \\
\hline$(2,200, .01)$ & 0.11 & 0.22 \\
\hline AVG & $\mathbf{0 . 1 2}$ & $\mathbf{0 . 1 6}$ \\
\hline
\end{tabular}

Table 1.3 presents the breakeven costs (\%) for double or out strategy relative to the unconditional buy-and-hold strategy. Buy and sell signals are generated from VMA and FMA rules for ASPI composite index are presented in the table. Rules are identified as (short, long, and band).

Table 1.3depicts the breakeven costs, which is the percentage round trip transaction costs need to offset the additional returns earned by the technical trading strategies relative to unconditional simple buy-and-hold strategy, for sixteen VMA and FMA rules applied to ASPI index. The actual total transaction cost of CSE till $31^{\text {st }}$ July 2010 was divided in to three layers as $1.4250 \%$ up to one million, $1.2250 \%$ over one million, and $0.4125 \%$ for over hundred million transactions. This cost structure was amended on august 2010 as $1.02 \%$ for transactions up to fifty million and $0.5125 \%$ for transaction more than fifty million. If investors assume the minimum costs $(0.4125)$ as the transaction cost it amounted to $0.825 \%$ to complete a round trip transaction. According to table 1.3 all VMA and FMA rules for ASPI composite index end up with positive breakeven transaction costs. But none of the moving average strategies on ASPI generates breakeven transaction costs greater than estimated actual transaction cost. Overall average breakeven transaction cost of VMA and FMA stands at $0.12 \%$ and $0.16 \%$ respectively, which are less than that of estimated actual transaction cost. However FMA rule has maintained a greater average value than the VMA rules.

\section{Findings and Discussion}

The main objective of the study is to test the profitability of the technical trading strategies after considering transaction costs. Referring to the objective, hypothesis one of the study mentioned that the breakeven transaction cost for technical trading strategy is greater than the 
estimated actual transaction cost. This study observed the profitability of technical trading strategies in CSE by using ASPI data. In the methodology part profitability is identified as returns from technical trading strategies in excess of unconditional buy-and-hold strategy after adjusting for transaction costs. Accordingly the estimated breakeven transaction costs are compared with estimated actual costs for ASPI. The results of the study revealed that the profits from the technical trading rules are impossible in CSE. The average breakeven costs across all VMA rules and FMA rules are less than the estimated actual transaction costs.

Although the moving average strategies are successful in forecasting stock price movements in overall market (using ASPI data), high transaction costs faded away the profit making opportunities for trading strategies. This indicates that the transaction costs are in a position to abolish technical trading profits. The technical trading strategies for ASPI are very much sensitive to the estimated actual transaction cost. Situation may be further aggravated if the study selects higher actual transaction cost instead of $0.825 \%$. According to the above findings this study rejects the hypothesis one "the breakeven transaction cost for technical trading strategy is greater than the estimated actual transaction cost".

In addition to main objective the study is mentioned as to examine whether the technical trading strategies can predict the stock price movements in CSE and the second hypothesis "Buy (sell) signals earn positive (negative) returns and the mean daily buy and sell returns generated from the technical trading strategies are significantly different from the returns earns from unconditional buy-and-hold strategy" is formulated to achieve this objective. According to the findings all sixteen VMA rules are statistically significant for ASPI data. (Statistical significance of a rule is accepted if buy returns, sell returns, and buy sell differences are significant). Out of sixteen FMA rules on ASPI only two generates statistically significant results while most of the individual sell signals and buy sell differences generate significant results. Both significant results came from higher shortperiods (two days) with $1 \%$ band. At the same time all the buy signals generate positive returns for both VMA and FMA and all the sell signals generate negative returns except (1, $50,0),(1,50,0.01)$ for FMA rules. Above results leads to accept the second hypothesis on VMA rules on ASPI data while results are not significant for FMA though they generated expected outcomes. This confirms that the VMA rules are in a position to predict stock price movements in CSE. 
When all above results taken in to account, hypothesis two is accepted for VMA rules for entire market (ASPI index). Tough other trading strategy, FMA, generates results in line with the hypothesis they are not statistically significant.

Findings of the study lead to a main recommendation to government authorities. The government can exploit this situation for financial sector developments. Throughout last four decades, Sri Lankan governments have used interest rate as a benchmark to attract the general public into savings by increasing nominal interest rates. This effort was not welcome by general public, due to higher inflation rates which led to minus real interest rates (Aluthge, 2000). This is one of the main reasons behind more local investors being attracted to the Sri Lankan share market. The stock market is still in a position to reduce its transaction costs further, without hampering the efficiency of the market. This probably would allure more and more domestic as well as global investors to endeavor investing in the Colombo share market, which in turn would maintain the momentum acquired in recent past.

\section{Limitations of the study}

The data series used in the study is not adjusted for the dividend payments. Colombo Stock Exchange started to calculate dividend adjusted return index from January 2004, so using that return index will avoid the employability of longer time period of data. On the other hand Brock et al. (1992) mentioned that the technical trading returns could not be distorted significantly with inclusion of dividends. The present study tested only two technical trading strategies which are commonly use by the market participants. But there are much more complex trading strategies uses by market participants which were not tested in this study.

\section{Directions to Further Research Areas}

This study analyze the data relating to market index, ASPI but testing of technical trading strategies in all sectors in CSE may be a good area study further. In addition to that analysis of individual company data may generate more different results and analysis of more complex technical trading strategies which were not test in this study will also be a good area for further research.

\section{List of References}

Alexander, S. S. (1964). Price movements in speculative markets: Trends or random walks, No. 2. Industrial management review, 5(2), 25-46. 
Aluthge, C. (2000). "Financial Sector Liberalisation in Sri Lanka: A Macro Level Inquiry into Capital Accumulation, Investment, Growth, and Stability", Vrije University Amsterdam.

Bessembinder, H. \& Chan, K. (1995). The profitability of technical trading rules in the Asian stock markets. Pacifi-basin journal,3, 257-284.

Bessembinder, H. \& Chan, K. (1998). Market efficiency and the returns to technical analysis. Financial Management, 27, 5-17.

Blume, L. Easley, D. \& O’Hara, M. (1994). Market statistics and technical analysis: The role of volume. Journal of Finance, 49, 153-181.

Bokhari, J., Cai, C., Hudson, R. \& Keasey, K. (2005). The predictive ability and profitability of technical trading rules: does company size matter? Economic letters, 86.

Brock, W. Lakonishok, J. \& LeBaron, B. (1992). Simple technical trading rules and the stochastic properties of stock returns. Journal of Finance 47(5), 1731-1764.

Cai, B. M., Cai, C. X., \& Keasey, K. (2005). Market efficiency and returns to simple technical trading rules: Further evidence from U.S, U.K, Asian and Chinese stock markets. Asia-pacific financial markets, 12(1), 45-60.

Central Bank of Sri Lanka, Annual Reports Varied Issues.

Chandrasekar, S. (2005). Simple technical trading strategies: return, risk, and size. Retrieved February 15, 2011, from http://ssrn.com/abstract=687177.

Colombo stock market. (n.d.). Retrieved January 2, 2012, from http://finance.mapsofworld.com/stock-market/colombo-stock-exchange.html

Gunasekarage, A. \& Power, D.M. (2001). The profitability of moving average trading rules in South Asian stock markets. Emerging markets review, 2, 17-33.

Gunasekerage, A. \& Power, D.M. (1995). A test of the weak-form of the efficient market hypothesis: Evidence using daily data from the Colombo Stock Exchange. Sri Lanka Journal of Social Sciences, 18, 41-53.

Hudson, R., Dempsey, M. \& Keasey, K. (1996). A note on the weak form efficiency of capital markets: the application of simple technical trading rules to UK stock prices -1935 to 1994. Journal of banking \& finance, 20, 1121-1132. 
James, Jr.,F.E. (1968). Monthly moving average- an effective investment tool? Journal of financial and quantitative analysis. 3, 315-326.

Lento, C. (2008). A combined signal approach to technical analysis on the S\&P 500. Journal of business \& economics research, 6 (8), 41-51.

Metghaalchi, M., Glasure, Y., Garza-Gomez, X., \& Chen, C. (2007). Profitable technical trading rules for the Australian stock market. International business \& economic research journal, 6(9), 49-58.

Murphy, J.J. (1999).Technical analysis of the financial markets. New York institute of finance.

Pathirawasam, C. \& Kral Milos (2011). Momentum effect and market states: Emerging market evidence. Economics and Management, Vol XV(2), 115-124.

Ratner, M. \& Leal, R. (1999). Test of technical trading strategies in the emerging equity markets of Latin America and Asia. Journal of banking and finance, 23(1).1887-1905

Reily, F. \& Brown, K. C. (2008). Investment analysis and portfolio management. $7^{\text {th }}$ Edition. South-Western College. 